\title{
EFFECT OF THERMAL EXPOSURE ON MICROSTRUCTURAL EVOLUTION IN ALLOY 718 FASTENERS
}

\author{
John F. Radavich** and Bernard H. Lawless \\ *Micro-Met Laboratories \\ West Lafayette, Indiana \\ $* *$ GE Aircraft Engines \\ Materials \& Process Engineering Department \\ Cincinnati, Ohio
}

\begin{abstract}
Alloy 718 bolts were microstructurally examined following thermal exposures of varying times at $538^{\circ} \mathrm{C}$ and $650^{\circ} \mathrm{C}$. For an exposure of 1400 hours at $538^{\circ} \mathrm{C}$, the presence of alpha- $\mathrm{Cr}$ precipitate was observed in the highly worked area of the thread root, but was not found in the shank body. For an exposure time of 3200 hours at $650^{\circ} \mathrm{C}$, the alpha-Cr phase was observed in both the thread root and shank body. Residual strain from cold work appears to accelerate the formation of alpha-Cr phase. The alpha-Cr phase is found to precipitate at the $\gamma$-delta phase interface, at grain boundaries, and in heavily deformed areas.
\end{abstract}




\section{Introduction}

Alloy 718 has been the subject of numerous thermal exposure studies in a temperature range of $593^{\circ} \mathrm{C}$ to $760^{\circ} \mathrm{C}$. [1-3] Barker, et al exposed alloy 718 at $593^{\circ} \mathrm{C}$ up to 21,500 hours and found no evidence of structural changes. Also, these exposures showed little influence on the stress rupture behavior.[1] Korth and Radavich reported yield strength, hardness, and impact energy data for exposures up to 50.000 hours at $593^{\circ} \mathrm{C} .650^{\circ} \mathrm{C}$, and $704^{\circ} \mathrm{C}$. [2] They found that the yield strength and hardness initially increased with exposure time at $593^{\circ} \mathrm{C}$, but the impact energy dropped $35 \%$ after 5.000 hours, and continued dropping to 50,000 hours. When alloy 718 was exposed at $650^{\circ} \mathrm{C}$ for 5,000 hours, the impact energy decreased nearly $70 \%$. For each of these exposures, an $\mathrm{aCr}$ precipitate was present; no other differences in microstructural features were observed. Studies of direct aged alloy 718 forgings by Shen, et al showed that an $\alpha \mathrm{Cr}$ phase can form faster when the amount of residual strain increases.[3] Nucleation of $\alpha \mathrm{Cr}$ always occurred faster in direct aged forgings as compared to solution + aged forgings. In the carly studies, $\alpha \mathrm{Cr}$ was identified by $\mathrm{x}$-ray diffraction of extracted residues, as metallographic techniques to observe the $\alpha \mathrm{Cr}$ in situ had not been developed.

In aerospace applications, alloy 718 bolts are typically used in a heat treat condition producing either $1240 \mathrm{MPa}$ or $1517 \mathrm{MPa}$ minimum tensile strength. The tensile strength can be manipulated by aging the bolt blank before or after thread rolling. Thread rolling after aging will produce the greater tensile strength. Since alloy 718 bolts contain high residual strain due to cold rolling, $\alpha \mathrm{Cr}$ formation may readily occur when the bolts are exposed in service at temperatures below $650^{\circ} \mathrm{C}$. This study will focus on the microstructural evolution in alloy 718 bolts with $1240 \mathrm{MPa}$ minimum tensile strength exposed at temperatures of $538^{\circ} \mathrm{C}$ and $650^{\circ} \mathrm{C}$.

\section{Procedure}

Alloy 718 bolts $(9.5 \mathrm{~mm}$ diameter) with $1240 \mathrm{MPa}$ minimum tensile strength were exposed up to 6800 hours at $538^{\circ} \mathrm{C}$, and up to 3200 hours at $650^{\circ} \mathrm{C}$. A survey of standard lot testing of 9.5 $\mathrm{mm}$ diameter bolts showed that the tensile strength is typically within a range of $1413 \mathrm{MPa}$ to $1545 \mathrm{MPa}$. Samples of the shank and the thread root areas were prepared to study the effects of residual strain on the microstructural changes.

All of the samples were electrolytically polished in a $20 \% \mathrm{H}_{2} \mathrm{SO}_{4}$ - methanol solution and electro-etched in a $\mathrm{CrO}_{3}$ acid solution. This preparation will cause the primary carbides, delta phase, and the $\gamma^{\prime \prime} / \gamma^{\prime}$ phases to be in relief, while any $\alpha \mathrm{Cr}$ that is present will be etched out.

\section{Results}

\section{Exposure at $538^{\circ} \mathrm{C}$}

At $538^{\circ} \mathrm{C}$, the shank of the bolt does not show any structural changes up to 6800 hours of exposure. Figure 1 shows the shank structure after 6800 hours exposure at $538^{\circ} \mathrm{C}$. Only the initial $\gamma / \gamma$ ' structure is discernible. In the thread root area, traces of $\alpha \mathrm{Cr}$ are barely perceptible after 400 hours exposure. However, $\alpha \mathrm{Cr}$ is readily observed in the thread root area after 1400 hours exposure and after 6800 hours exposure. Figures 2(b) and 2(d) show the $\alpha \mathrm{Cr}$ in the thread root region after 1400 hours and 6800 hours of exposure, respectively. A greater amount of $\alpha \mathrm{Cr}$ is seen after 6800 hours of exposure. 

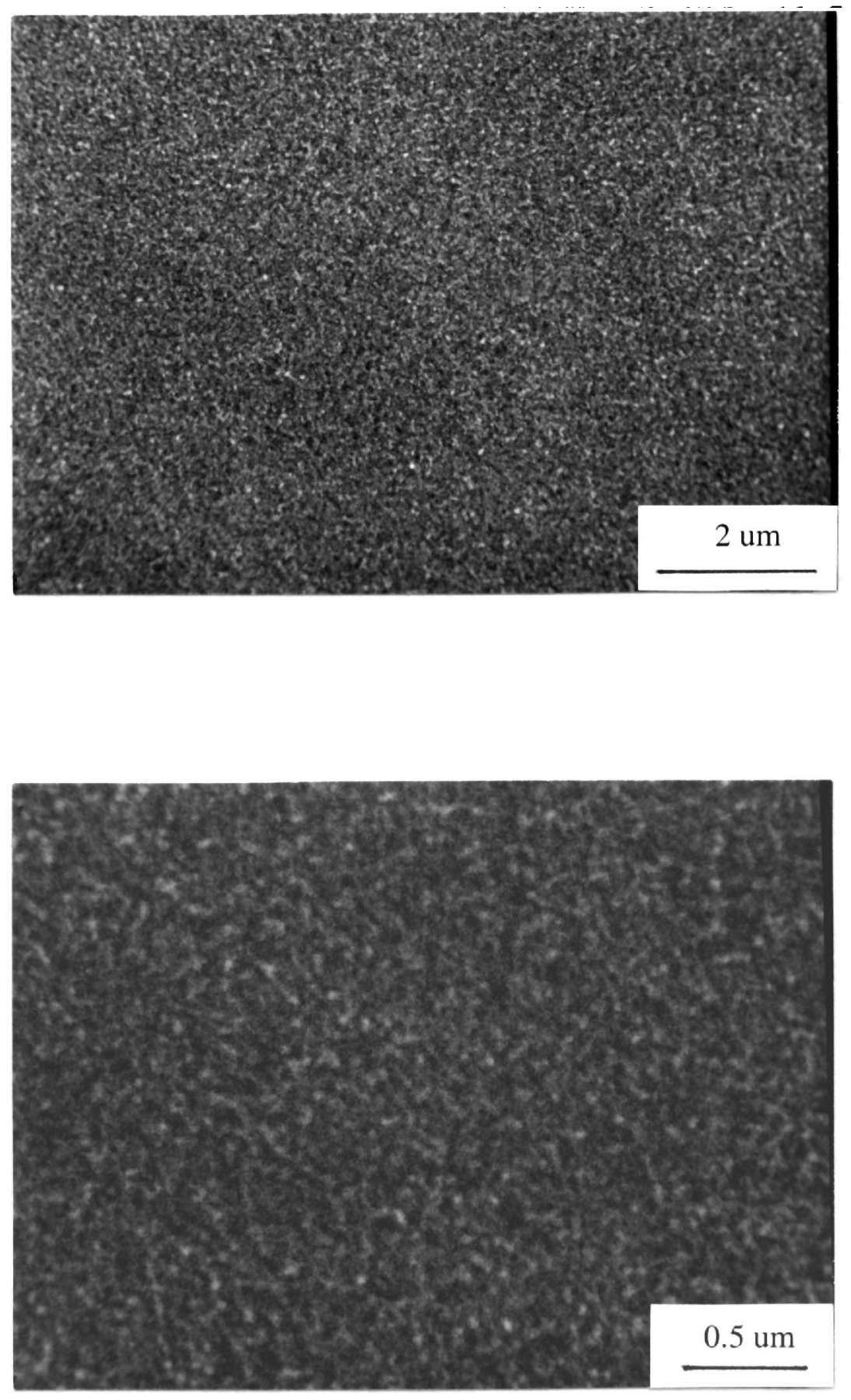

Figure 1 . Shank region of alloy 718 bolt after an exposure of $538^{\circ} \mathrm{C} / 6800$ hours. 


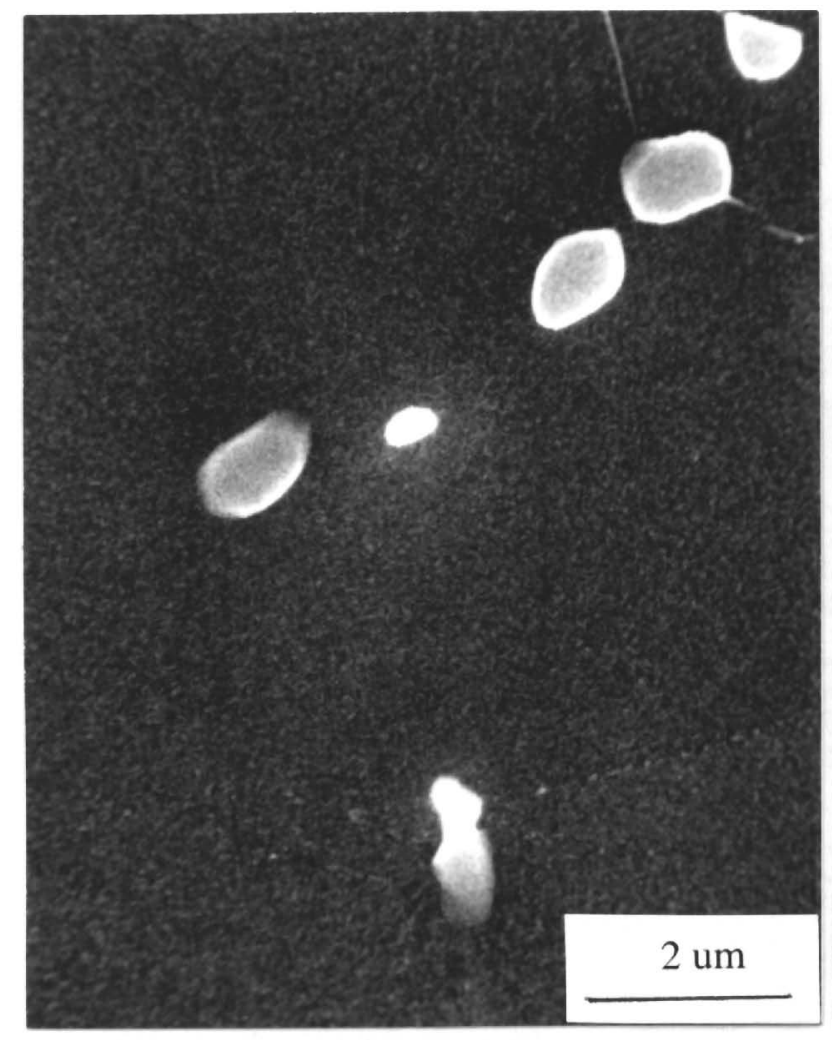

a) Shank region/1400 hours

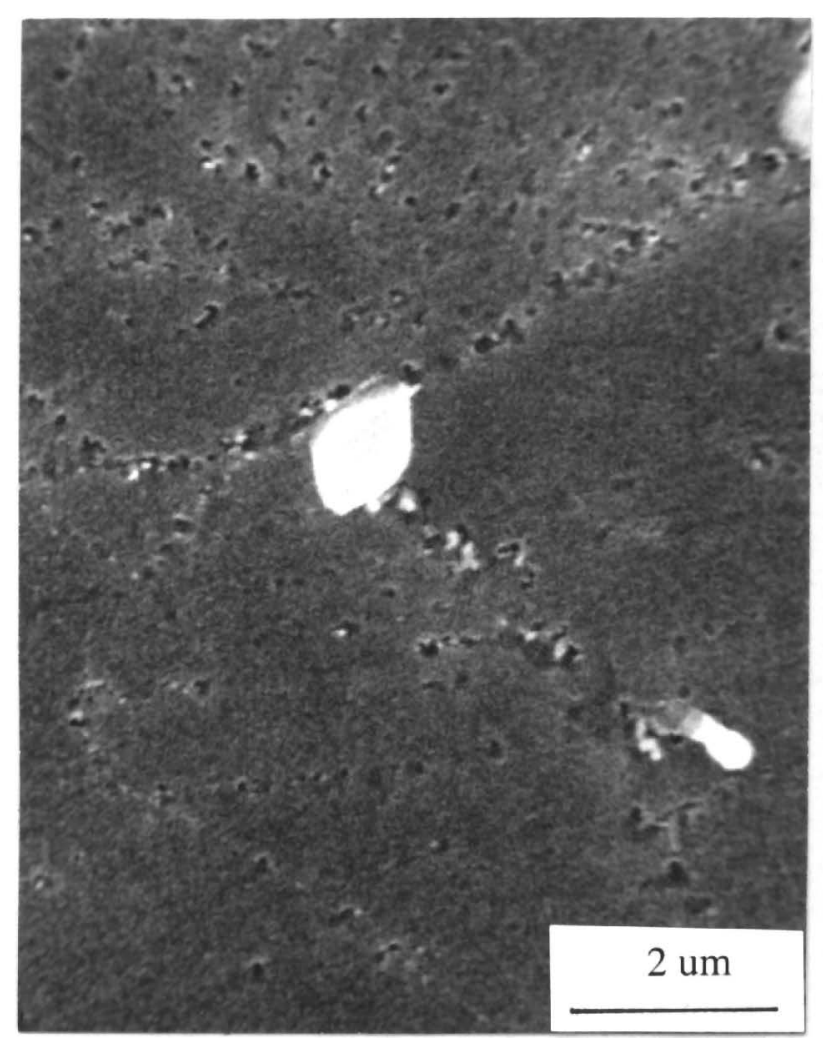

b) Thread root region/1400 hours

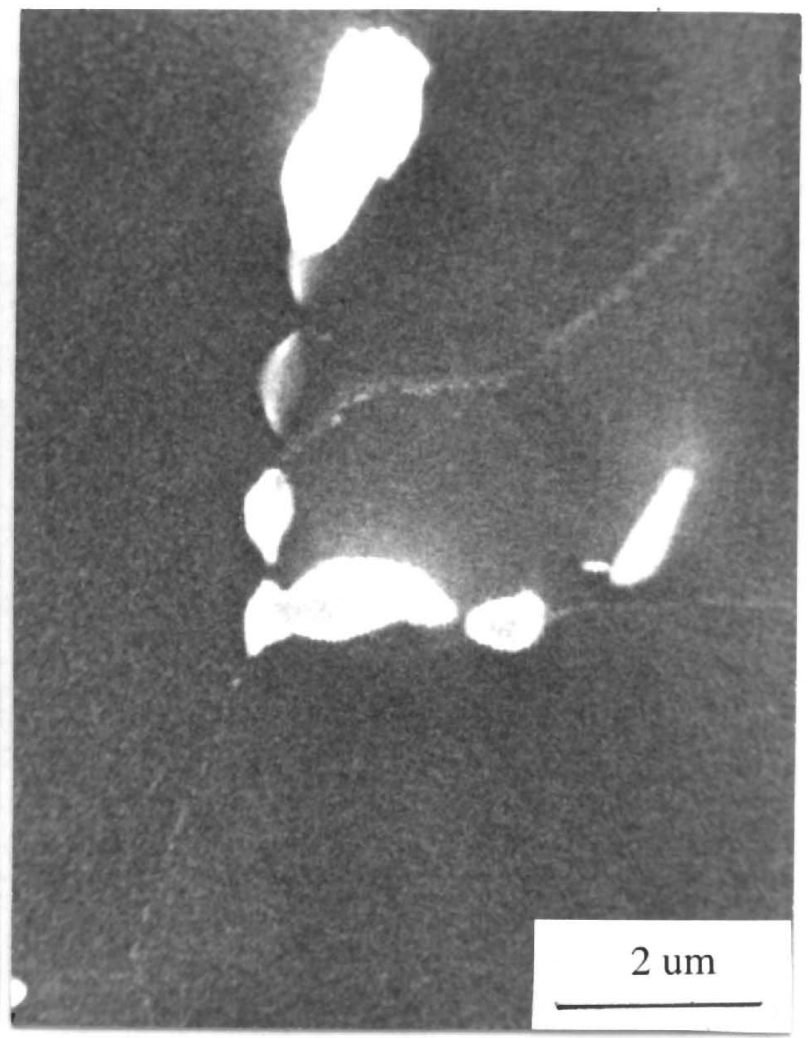

c) Shank region/6800 hours

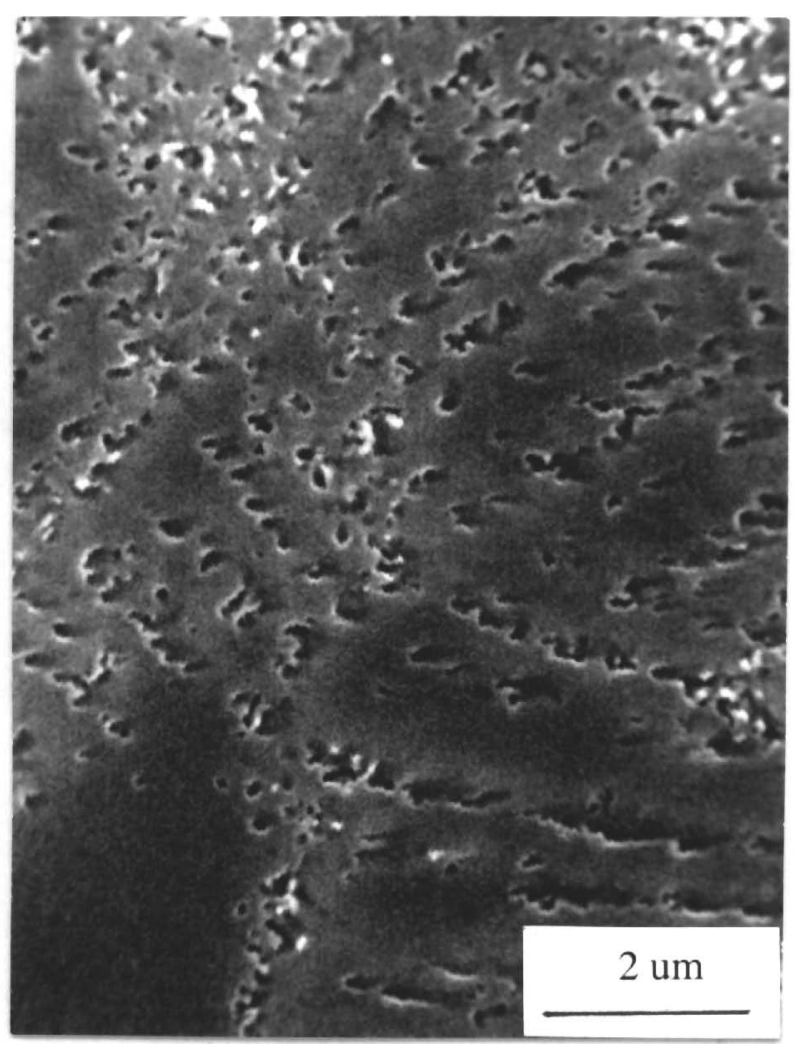

d) Thread root region/6800 hours

Figure 2. Alloy 718 bolts after an exposure at $538^{\circ} \mathrm{C}$. 
To confirm the structure as $\alpha \mathrm{Cr}$, the 1400 hour and 6800 hour samples from the thrad root were re-prepared with another electrolytic preparation in which the $\alpha \mathrm{Cr}$ is in relief. Figure 3 shows the $\alpha \mathrm{Cr}$ in relief after 1400 and 6800 hours exposure at $538^{\circ} \mathrm{C}$. The $\alpha \mathrm{Cr}$ precipitation appears to align with a deformed grain pattern.

\section{Exposure at $650^{\circ} \mathrm{C}$}

After 50 and 800 hours at $650^{\circ} \mathrm{C}$, the thread root regions already exhibit an $\alpha \mathrm{Cr}$ network, as seen in Figures 4(b) and 4(d), respectively. In contrast, Figure 4(c) shows very little, if any, structural change in the shank after $650^{\circ} \mathrm{C} / 800$ hours exposure. The size of the $\alpha \mathrm{Cr}$ in the thread root region after 50 hours at $650^{\circ} \mathrm{C}$ is similar in size to that found after 1400 hours at $538^{\circ} \mathrm{C}$ (Figure 2(b)).

Noticeable structural changes are observed after 3200 hours at $650^{\circ} \mathrm{C}$. Transition delta phase, coalescence of $\gamma^{\prime \prime}$, and large $\alpha \mathrm{Cr}$ precipitates can be seen in the thread root in Figure 5(c). Figure $5(\mathrm{a})$ shows less structural change in the middle of the shank, although the beginning of ( $\mathrm{Cr}$ formation can be seen.

\section{Discussion}

The obvious appearance of $\alpha \mathrm{Cr}$ in the thread root areas after 1400 hours at $538^{\circ} \mathrm{C}$ is surprising in view of the absence of similar changes in the shank area. Even after 6800 hours at $538^{\circ} \mathrm{C}$, the shank area, containing less residual strain than the thread root, shows no evidence of $\alpha \mathrm{Cr}$. The magnitude of residual strain from cold rolling the threads is unknown. However, it is apparent that residual strain has reduced the exposure conditions required for precipitation of $\alpha \mathrm{Cr}$ in alloy 718. A summary of the observations of $\alpha \mathrm{Cr}$ in this study can be seen in Table $\mathrm{I}$. The initial condition of alloy 718 material prior to bolt manufacture may play an important role in the precipitation of $\alpha \mathrm{Cr}$. A bolt from another source was exposed at $650^{\circ} \mathrm{C}$ for the same 3200 hours. Micrographs from the shank and thread root regions can be seen in Figure 6 . Comparison of the thread root regions in Figures 5 and 6 shows that the development of transition delta phase, coalescence of $\gamma^{\prime \prime}$, and precipitation of $\alpha \mathrm{Cr}$ is not the same for the two bolts, and may be dependent on the initial microstructure.

Table I Observations of $\alpha \mathrm{Cr}$ in Alloy 718 bolts

\begin{tabular}{cccc}
\hline $\begin{array}{c}\text { Exposure } \\
\text { temp } \\
\left({ }^{\circ} \mathrm{C}\right)\end{array}$ & $\begin{array}{c}\text { Exposure } \\
\text { time } \\
\text { (hours) }\end{array}$ & $\begin{array}{c}\alpha \mathrm{Cr} \\
\text { observed in } \\
\text { shank }\end{array}$ & $\begin{array}{c}\alpha \mathrm{Cr} \\
\text { observed in } \\
\text { thread root }\end{array}$ \\
\hline 538 & 400 & No & Yes \\
538 & 1400 & No & Yes \\
538 & 6800 & No & Yes \\
650 & 50 & No & Yes \\
650 & 800 & No & Yes \\
650 & 3200 & Yes & Yes \\
\hline
\end{tabular}




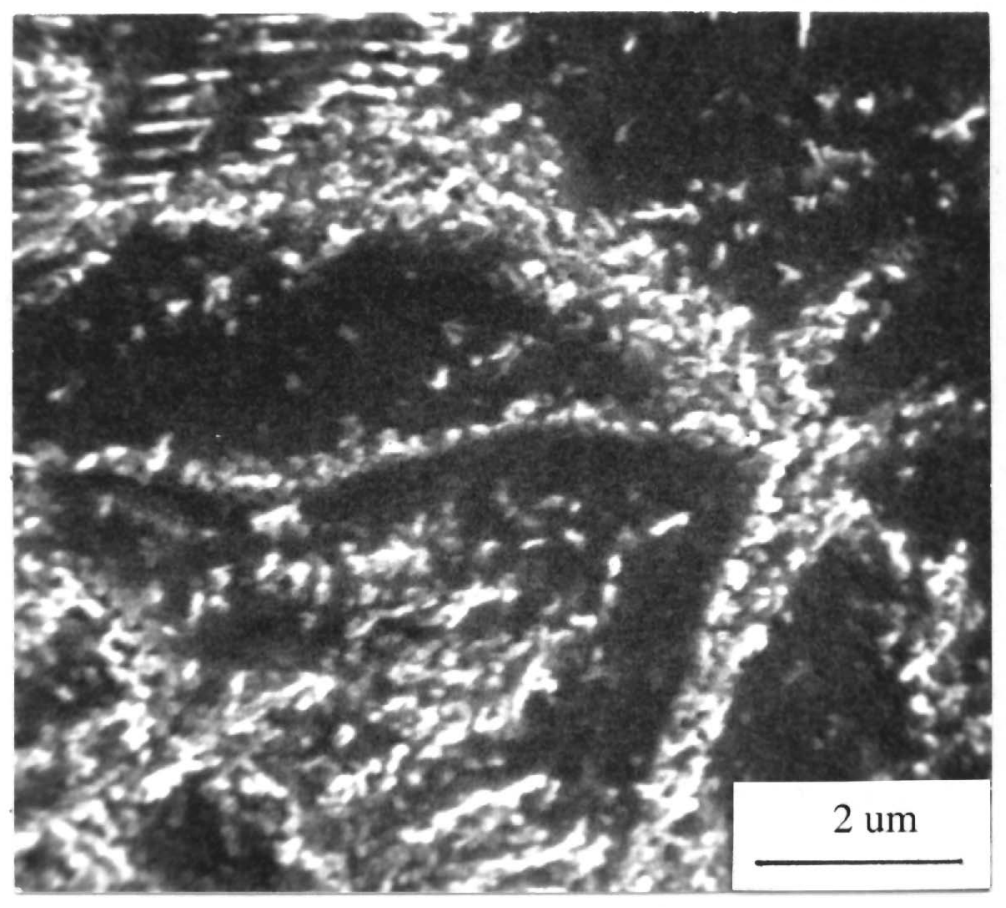

a) 1400 hours exposure

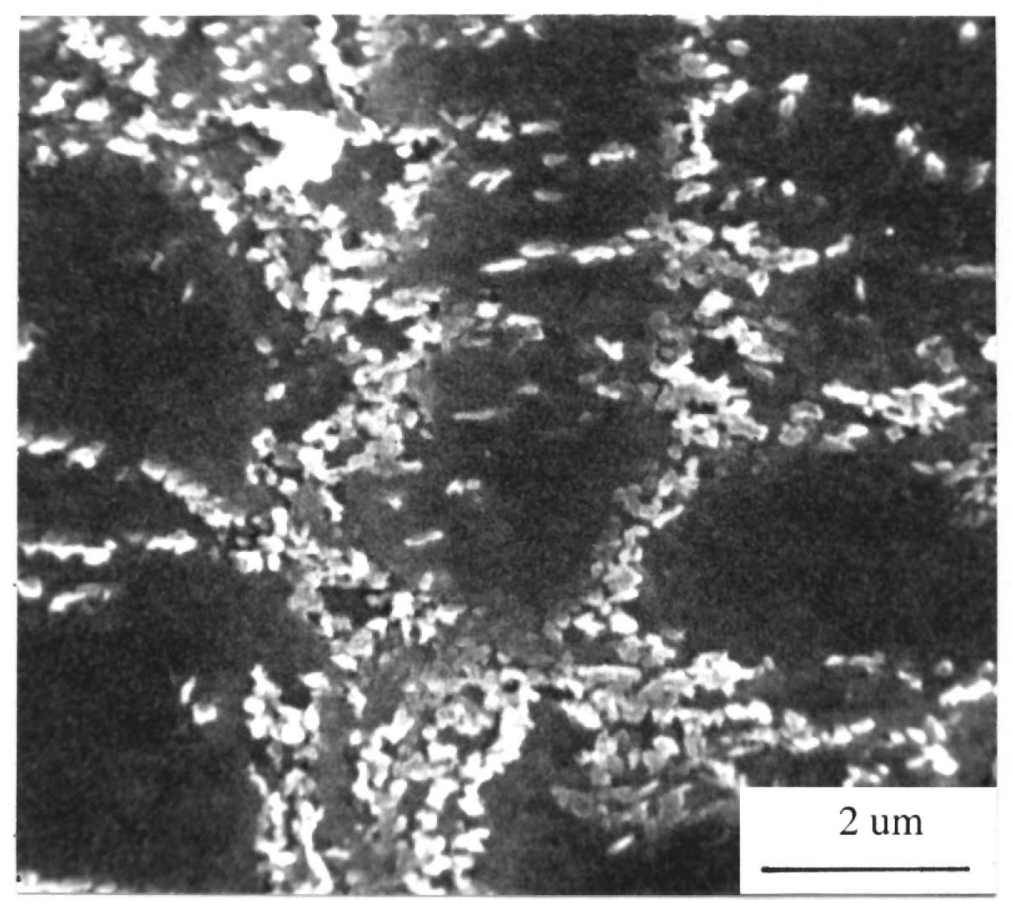

b) 6800 hours exposure

Figure 3. Alloy 718 bolt after an exposure at $538^{\circ} \mathrm{C}$. Samples from the thread root region have been prepared so that $\alpha \mathrm{Cr}$ is in relief. 


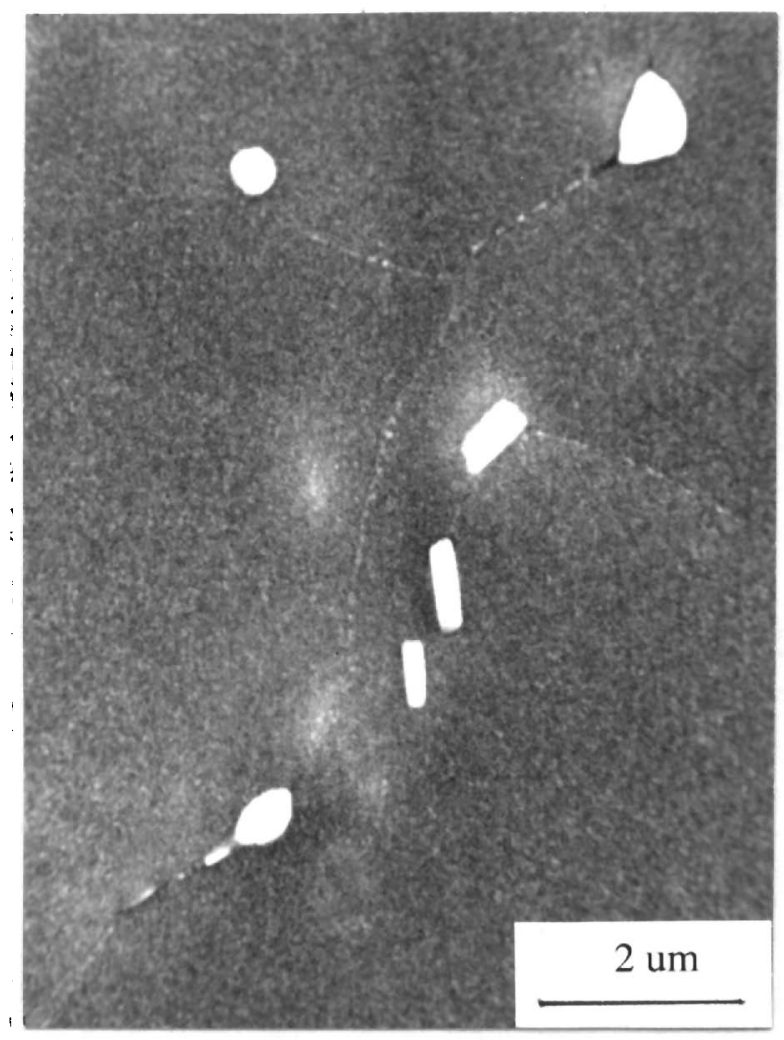

a) Shank region/50 hours

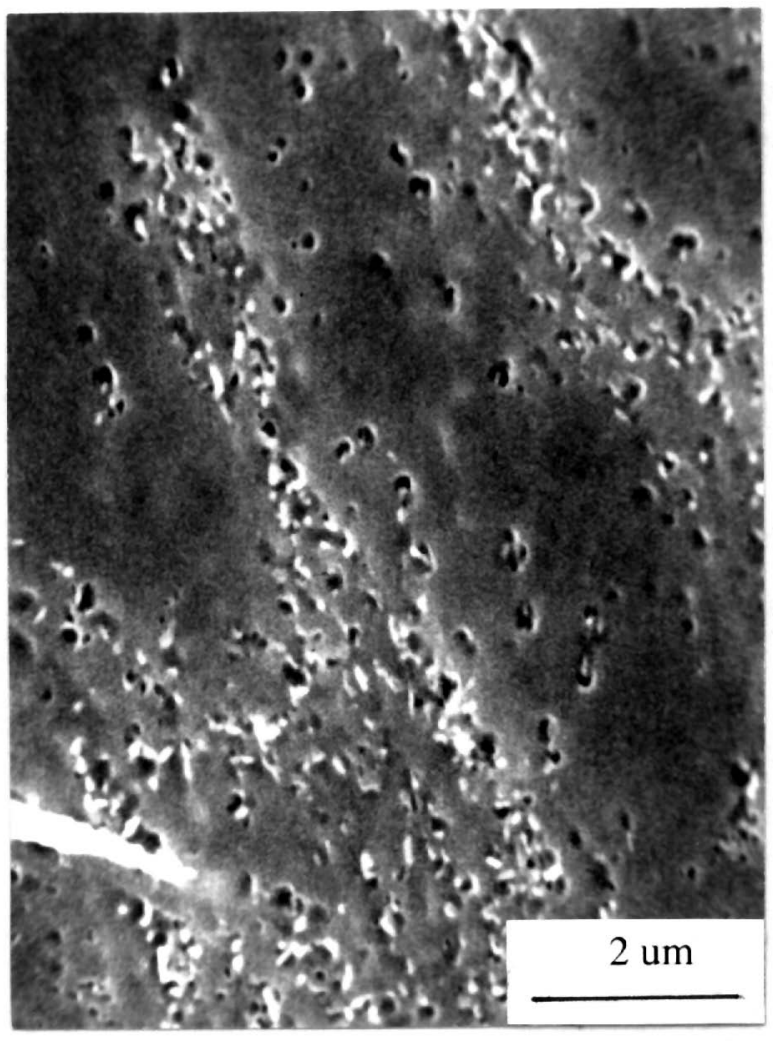

b) Thread root region/50 hours

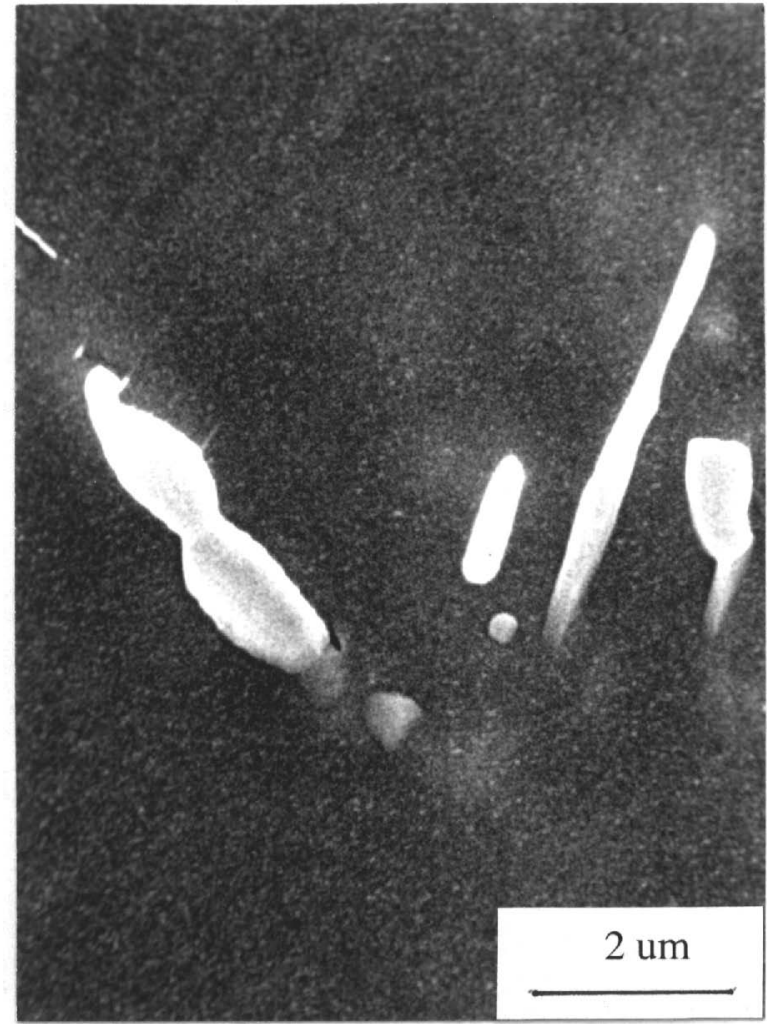

c) Shank region/800 hours

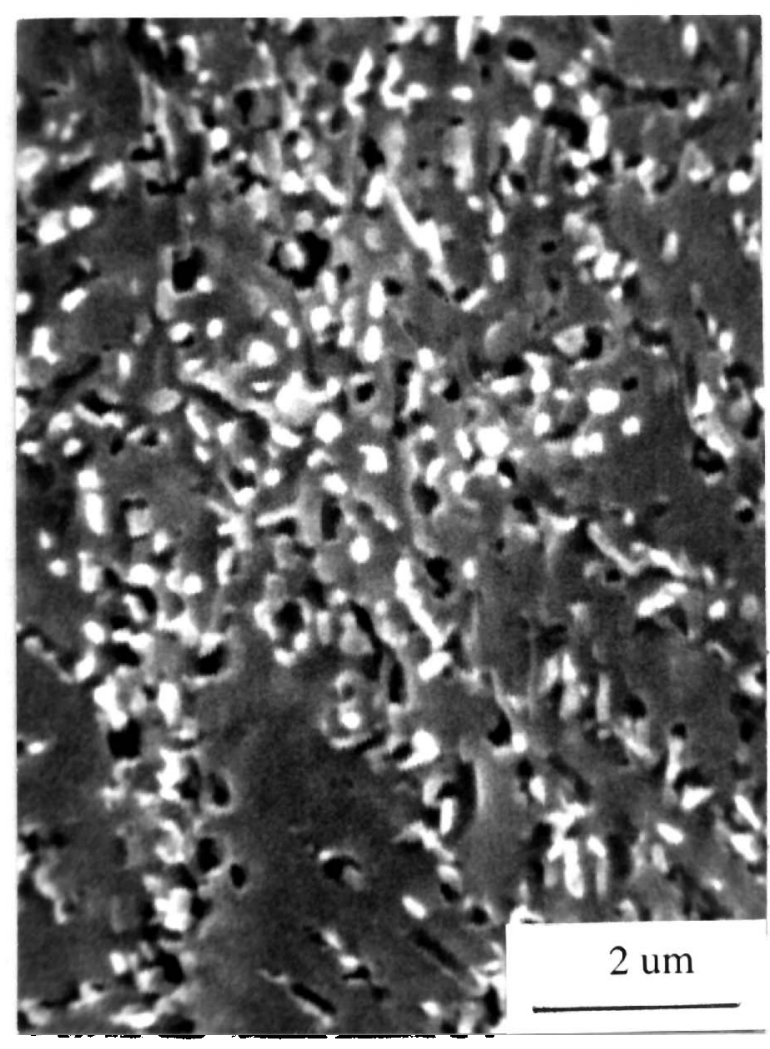

d) Thread root region/800 hours

Figure 4. Alloy 718 bolts after an exposure at $650^{\circ} \mathrm{C}$. 


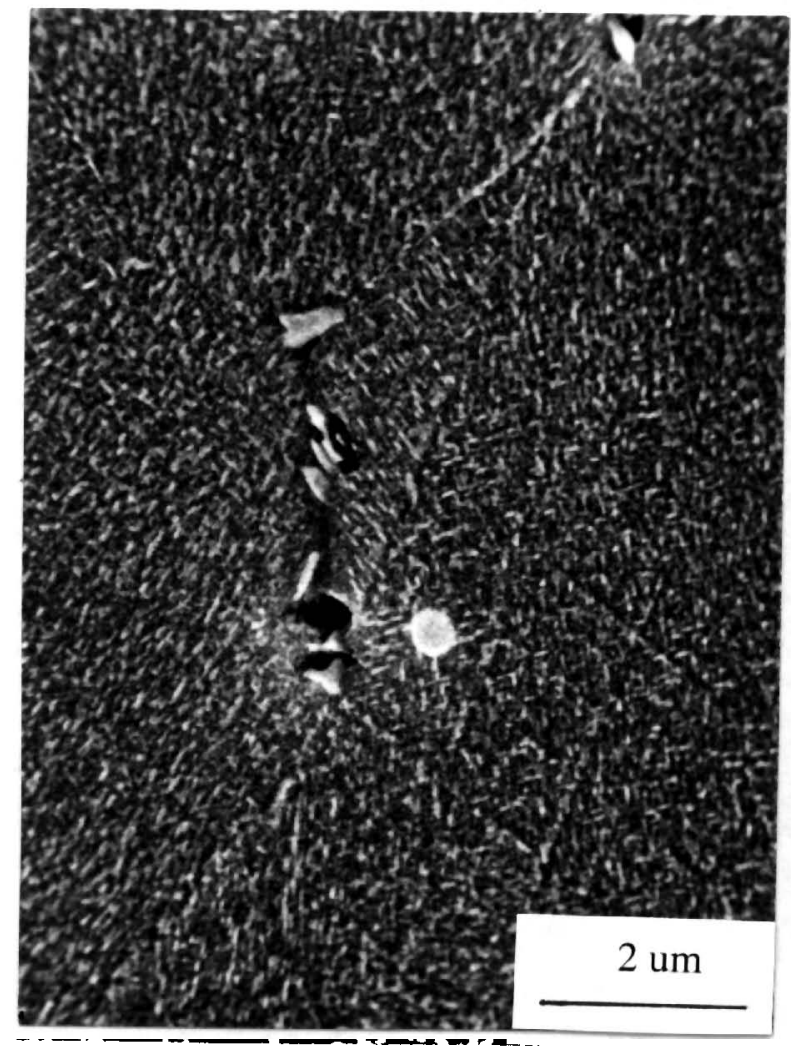

a) Shank region

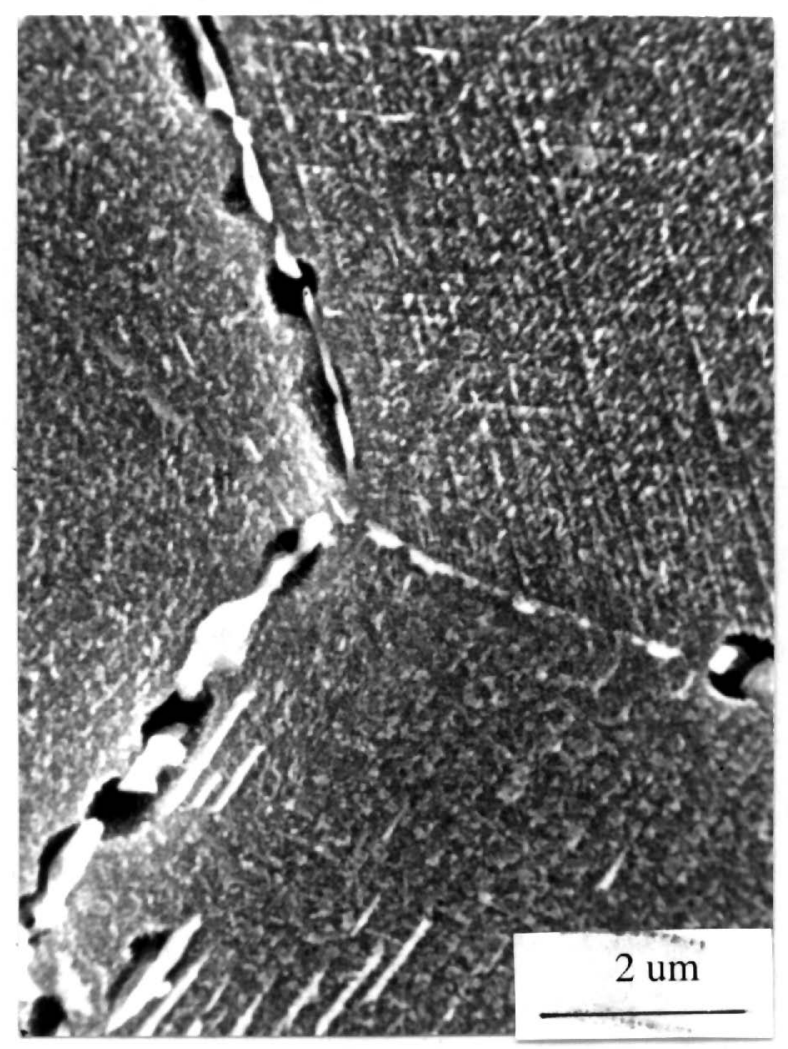

b) Region between center of shank and thread root

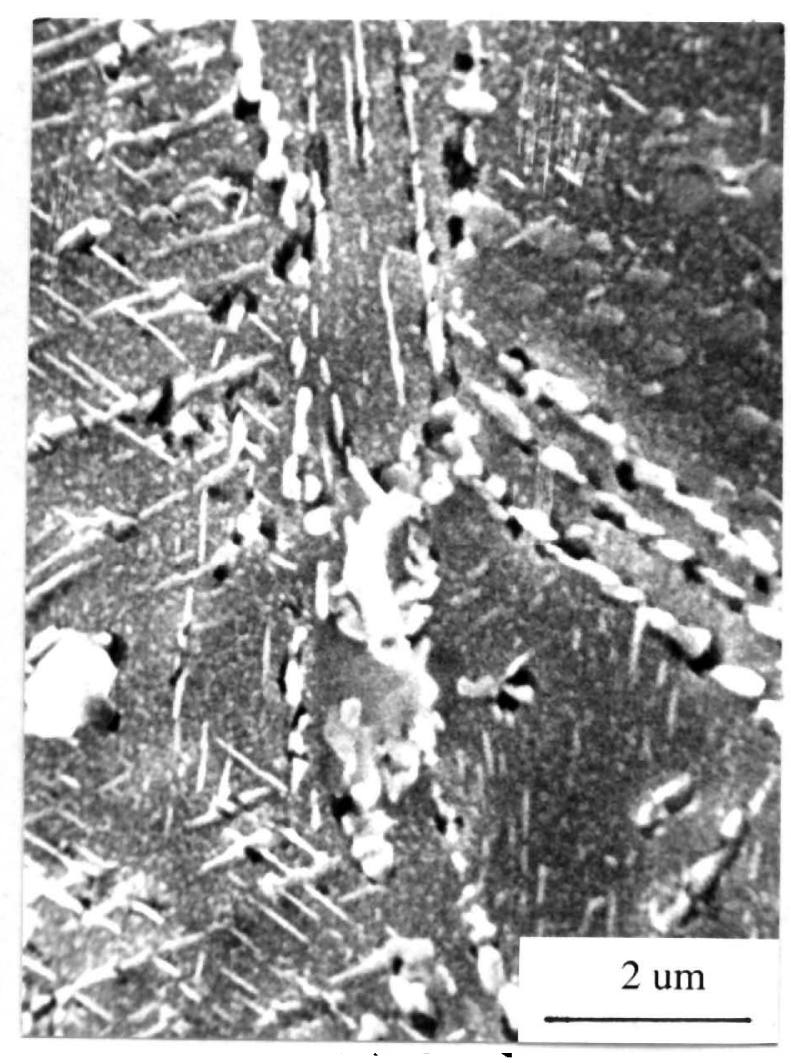

c) Thread root region

Figure 5 . Alloy 718 bolts after an exposure at $650^{\circ} \mathrm{C} / 3200$ hours. 


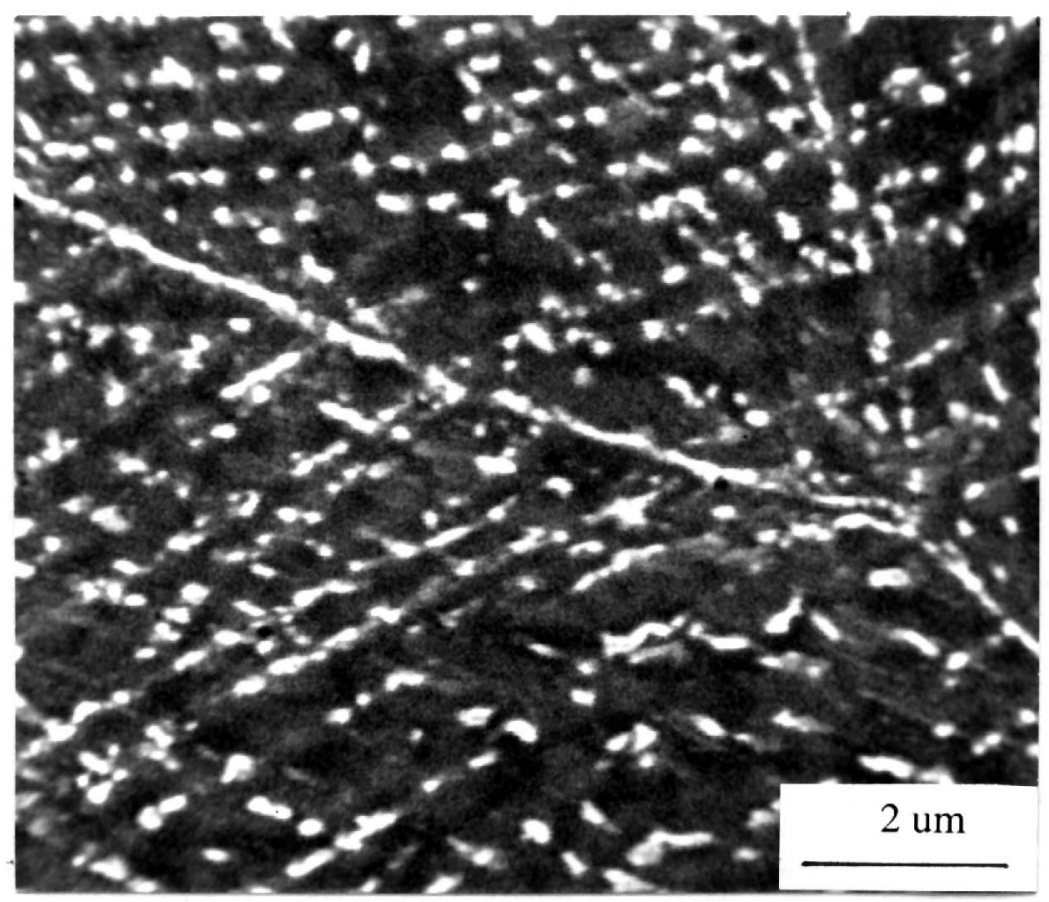

a) Shank region

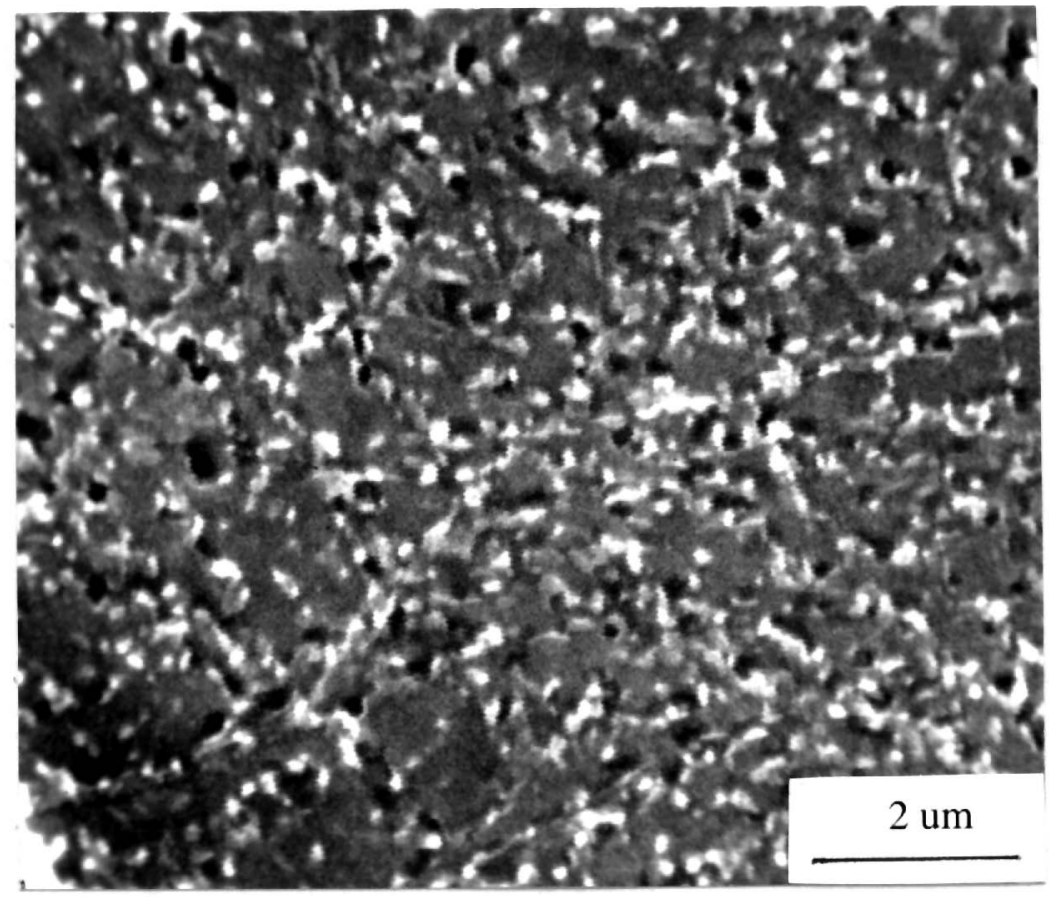

b) Thread root region

Figure 6. Alloy 718 bolts from another source after an exposure at $650^{\circ} \mathrm{C} / 3200$ hours. 


\section{Conclusions}

1. Residual strain in the thread root area of the bolt has accelerated the formation of $\alpha \mathrm{Cr}$ at $538^{\circ} \mathrm{C}$ and at $650^{\circ} \mathrm{C}$. The $\alpha \mathrm{Cr}$ structure was clearly observed and documented in the thread root after 1400 hours exposure at $538^{\circ} \mathrm{C}$, and after 50 hours exposure at $650^{\circ} \mathrm{C}$.

2. The shank region does not exhibit structural changes up to 6800 hours at $538^{\circ} \mathrm{C}$.

3. The shank center shows some $\gamma^{\prime \prime}$ coalescence and the beginning of $\alpha \mathrm{Cr}$ formation after 3200 hours at $650^{\circ} \mathrm{C}$. $\alpha \mathrm{Cr}$ precipitates and transitional delta plates appear in the region between the shank and thread root, and are more numerous in the thread root area.

\section{References}

1. J.F. Barker, E.W. Ross, and J.F. Radavich, "Long Time Stability of Inconel 718", Journal of Metals, January $1970,31$.

2. J.F. Radavich and G.E. Korth, "High Temperature Degradation of Alloy 718 after" Longtime Exposures", Superalloys 1992, eds. S.D. Antolovich, et al, (TMS, 1992), 497506.

3. G. Shen, et al, "The Effects of Processing on Stability of Alloy 718", Superalloys 2000, eds. T.M. Pollock, et al, (TMS, 2000), 445-448. 